\title{
Pemanfaatan Teknologi Informasi sebagai Media Pembelajaran di Taman Pendidikan al-Quran
}

\author{
Maftahatul Hakimah \\ Institut Teknologi Adhi Tama Surabaya
}

\author{
Tukadi \\ Institut Teknologi Adhi Tama Surabaya
}

\section{Rinci Kembang Hapsari}

Institut Teknologi Adhi Tama Surabaya

\author{
Hendro Nugroho \\ Institut Teknologi Adhi Tama Surabaya
}

Dian Puspita Hapsari

Institut Teknologi Adhi Tama Surabaya

\begin{abstract}
The development of information technology now provides easy access in all fields even though non-formal education such as Taman Pendidikan al-Quran (TPQ). Pleasant learning is a demand for TPQ teachers including TPQ Al-Fadlol so that the santri can understand religious material so that it can be applied in daily routines. Daily worship material taught in Al-Fadlol TPQ is daily prayer, guidance for prayer and Islamic stories. The Community Service activities carried out are presenting the main material in TPQ Al-Fadlol in an application called Muslim Daily Prayer as a learning medium. With this application, the students and the teachers can create a learning environment that is not boring so that the students are more eager to learn religion. In addition, the socialization of the positive and negative influences of information technology was provided to equip the santri and the teachers to be wise in using it.
\end{abstract}

Keywords: Muslim Daily Prayer; Information technology; Instructional media

\begin{abstract}
Abstrak
Perkembangan teknologi informasi saat ini memberikan kemudahan akses disegala bidang sekalipun pendidikan non formal seperti Taman Pendidikan al-Quran (TPQ). Cara belajar yang menyenangkan menjadi tuntutan bagi para guru TPQ termasuk di TPQ Al-Fadlol agar para santri bisa memahami materi agama sehingga bisa diterapkan dalam rutinitas keseharian. Materi ibadah sehari-hari yang diajarkan di TPQ Al-Fadlol ini adalah doa sehari-hari, tuntunan shalat dan cerita islami. Kegiatan Pengabdian Kepada Masyarakat yang dilakukan ini adalah menyajikan materi utama di TPQ Al-Fadlol dalam sebuah aplikasi yang diberi nama Muslim Daily Prayer sebagai media pembelajaran. Dengan aplikasi ini, para santri dan para guru bisa menciptakan suasana belajar yang tidak membosankan sehingga para santri lebih bersemangat belajar agama. Selain itu, sosialisasi terhadap pengaruh positif dan negatif dari adanya teknologi informasi ini diberikan untuk membekali para santri dan para guru agar lebih bijak dalam menggunakannya.
\end{abstract}

Kata Kunci: Muslim Daily Prayer; Teknologi informasi; Media pembelajaran

\section{Pendahuluan}

Teknologi informasi saat ini menjadi sebuah kebutuhan dalam berbagai bidang, terutama dalam bidang pendidikan. Teknologi informasi pada dunia pendidikan bertujuan untuk memudahkan para pendidik dan peserta didik dalam proses belajar (Budiman, 2017). Sering kali, kejenuhan para peserta didik menjadi suatu permasalahan tersendiri bagi para guru selaku pendidik. Salah satu cara yang digunakan untuk mengatasi hal tersebut adalah digunakannya media pembelajaran yang menarik minat belajar dan antusias peserta didik sehingga tujuan pendidikan bisa tercapai. Pemanfaatan teknologi menjadi salah satu pilihan dalam mengonversi metode pembelajaran yang konvensional menjadi metode yang menyenangkan bagi anak-anak 
usia pelajar. Bentuk media pembelajaran berbasis teknologi informasi bisa berupa internet, intranet, mobile phone, dan CD-ROM atau flash disk (Muhson, 2010).

Taman Pendidikan al-Quran (TPQ) adalah lembaga atau kelompok masyarakat yang menyelenggarakan pendidikan nonformal jenis keagamaan Islam yang bertujuan untuk memberikan pengajaran membaca alquran sejak usia dini serta memahami dasar-dasar agama Islam pada anak usia taman kanak-kanak, sekolah dasar, dan atau madrasah ibtidaiyah (SD/MI), atau bahkan yang lebih tinggi (Anonim, 2019). Dalam hal pembelajaran, lembaga ini pada umumnya masih menerapkan metode konvensional. Begitu pun dengan pembelajaran yang ada di TPQ Al-Fadlol yang beralamat di Jalan Wirabumi No. 37 RT. 01 RW. 08, Gedangan, Sidoarjo. Metode yang diterapkan di TPQ ini juga menggunakan sistem klasikal dan setoran. Klasikal artinya para santri belajar secara bersamaan dalam satu kelas, sedangkan setoran dilakukan setiap santri secara individu untuk mengetahui kemampuan mengaji mereka. Dengan cara belajar ini, para santri (sebutan untuk peserta didik TPQ) kadang kurang bersemangat untuk berangkat belajar. Oleh karena itu, tim pengabdian kepada masyarakat akan mengembangkan media pembelajaran berbasis teknologi informasi di TPQ Al-Fadlol untuk meningkatkan minat belajar para santri dalam belajar ilmu agama.

Media pembelajaran dipilih sebagai tema kegiatan pengabdian masyarakat karena dapat meningkatkan kualitas hasil belajar peserta didik, selain proses pembelajaran yang lebih jelas dan menarik. Daya tangkap peserta didik sangat dipengaruhi oleh model aktivitas belajar yang dilakukan guru. Jika pembelajaran hanya terpusat pada guru, daya serap peserta didik hanya sekitar 5\%. Daya serap ini akan meningkat sampai 90\% pada saat peserta didik ini belajar bersama teman sebayanya (Muhson, 2010). Kegiatan pembelajaran menuntut dikuranginya metode ceramah dan diganti dengan pemakaian banyak media. Lebih-lebih pada kegiatan pembelajaran saat ini yang menekankan pada keterampilan proses dan active learning maka kiranya peranan media pembelajaran menjadi semakin penting (Nurseto, 2012). Oleh karena itu, pada kegiatan PKM ini dibuat sebuah aplikasi yang akan membantu proses pembelajaran di TPQ Al-Fadlol. Aplikasi ini berbasis Android dengan konten berupa materi yang diajarkan di TPQ, yaitu doa sehari-hari, tuntunan salat, dan cerita islami.

Tim PKM sangat menyadari bahwa perkembangan teknologi saat ini juga sangat berpengaruh pada perkembangan psikologi anak. Oleh karena itu, selain menyediakan aplikasi sebagai media pembelajaran yang baru, tim PKM juga membekali pengetahuan kepada para santri dan guru terkait pengaruh dari teknologi informasi. Hal ini dilakukan agar para peserta PKM bisa mengurangi dampak negatif yang ditimbulkan akibat seringnya menggunakan perangkat teknologi informasi (Ameliola \& Nugraha, 2015).

\section{Metode Pelaksanaan}

Untuk mengatasi permasalahan yang telah dibahas maka pelaksanaan PKM ini akan dilakukan dengan tahapan yang diberikan pada diagram alir Gambar 1.

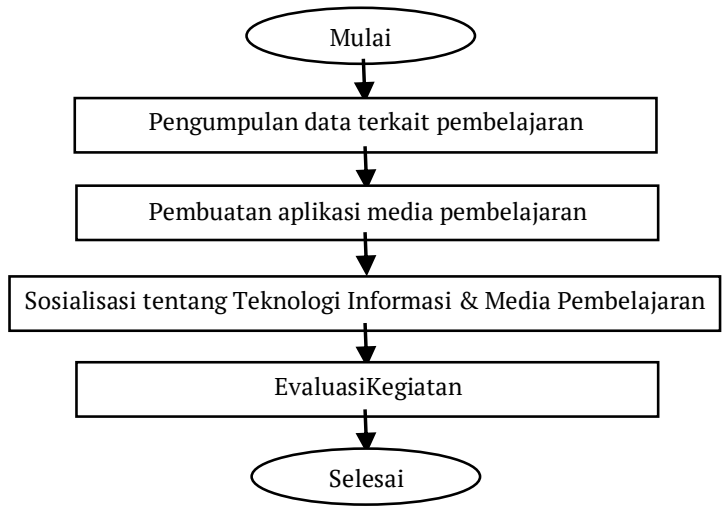

Gambar 1. Tahapan Pelaksanaan PKM 
Gambar 1 merupakan urutan pelaksanaan kegiatan PKM. Kegiatan dimulai dengan mengumpulkan informasi yang berhubungan dengan pembelajaran di TPQ. Pengumpulan data ini dilakukan melalui wawancara dengan para guru dan pengamatan langsung pada kondisi di lapangan. Dari tahap ini, tim PKM mengetahui perlunya media pembelajaran yang menarik sesuai dengan tingkat usia para santri. Materi pembelajaran yang akan dimasukkan pada media adalah materi tuntunan salat, doa sehari-hari, dan cerita islami. Media pembelajaran yang akan dibuat tim PKM ini berupa aplikasi berbasis Android dengan tampilan yang akan membuat belajar agama di TPQ menjadi menyenangkan. Tahap berikutnya adalah melakukan sosialisasi tentang teknologi informasi. Sosialisasi ini perlu dilakukan untuk membekali para santri dalam menghadapi pesatnya perkembangan teknologi yang kadang kala menyajikan informasi yang tidak bertanggung jawab. Bersamaan dengan sosialisasi tersebut, diluncurkan juga aplikasi media pembelajaran yang akan digunakan untuk membantu mereka dalam belajar. Setelah kegiatan tersebut dilakukan, evaluasi dilakukan untuk mengetahui kinerja yang sudah dilakukan oleh tim PKM. Sesuai dengan isi dari apilkasi yang dibuat oleh tim PKM maka aplikasi ini diberi nama Muslim Daily Prayer. Materi yang diberikan oleh tim PKM dan metode pelaksanaanya dapat dilihat pada Tabel 1.

Tabel 1. Jenis Kegiatan PKM

\begin{tabular}{ccl}
\hline No. & \multicolumn{1}{c}{ Kegiatan } & \multicolumn{1}{c}{ Metode } \\
\hline 1 & Sosialisasi Perkembangan & Acara ini ditujukan kepada para santri dan guru TPQ \\
& Teknologi Informasi & Al-Fadlol agar siap dengan perkembangan teknologi saat \\
& & ini dan tidak terpengaruh dengan berita-berita hoaks (yang \\
& & belum tentu kebenarannya). Konsep acara dibuat interaktif \\
& & dengan memberikan pertanyaan seputar teknologi \\
& & informasi kepada audiens dan memberikan hadiah bagi \\
& & peserta yang bisa menjawab. \\
\hline 2 & Pelatihan Penggunaan & Pelatihan ini melibatkan para santri dan juga guru untuk \\
& Aplikasi Muslim Daily & melatih mereka menggunakan aplikasi yang sudah \\
& Prayer sebagai Media & disesuaikan dengan kebutuhan. Pada kegiatan ini juga \\
& Pembelajaran & diberikan pemahaman kepada peserta batasan-batasan \\
& & dalam penggunaan gadget (handphone) sebagai salah satu \\
& & perangkat teknologi informasi. Penjelasan interaktif selalu \\
& & diberikan agar kegiatan berlangsung menyenangkan. \\
\hline
\end{tabular}

Tabel 1 menjelaskan kegiatan utama dari PKM. Kegiatan dimulai dengan sosialisasi perkembangan teknologi informasi. Agar tujuan sosialisasi tercapai maka metode yang digunakan tim PKM adalah memberikan presentasi dalam bentuk yang interaktif seperti mengajak diskusi para santri, memberikan sesi tanya jawab dan hadiah bagi peserta yang aktif. Acara kedua yaitu memberikan pelatihan kepada para santri dan para guru TPQ dalam menggunakan Aplikasi Muslim Daily Prayer. Konsep acara disusun semenarik mungkin agar aplikasi ini bisa dimanfaatkan dengan sebaik-baiknya.

\section{Hasil dan Pembahasan}

Kegiatan PKM telah dilaksanakan dengan baik dan lancar. Berdasarkan tahapan pelaksanaan PKM, berikut ini akan diberikan hasil yang telah dicapai dan pembahasan oleh tim PKM pada TPQ Al-Fadlol. 


\section{a. Tampilan Aplikasi Muslim Daily Prayer}

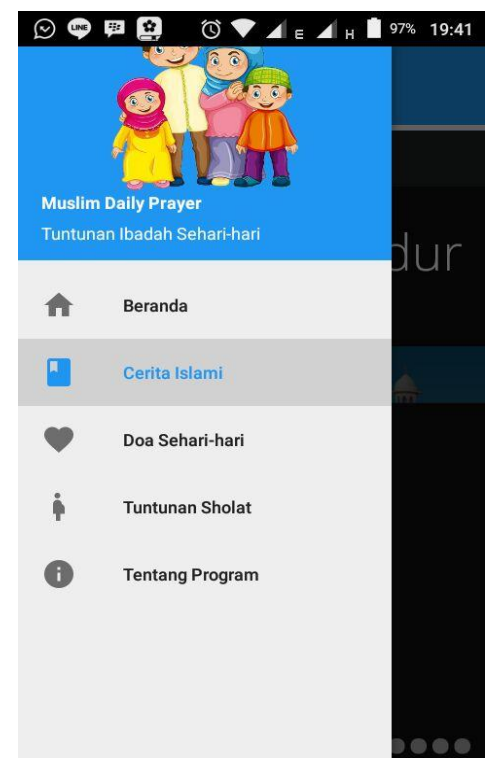

Gambar 2. Tampilan Awal Aplikasi Muslim Daily Prayer

Gambar 2 merupakan bentuk tampilan aplikasi yang telah berhasil dibuat oleh tim PKM. Sesuai dengan materi pembelajaran, menu yang ada di halaman awal tersebut adalah cerita islami, doa sehari-hari, dan tuntunan salat. Gambar dan karakter yang dibuat sangat sesuai untuk para santri TPQ Al-Fadlol.

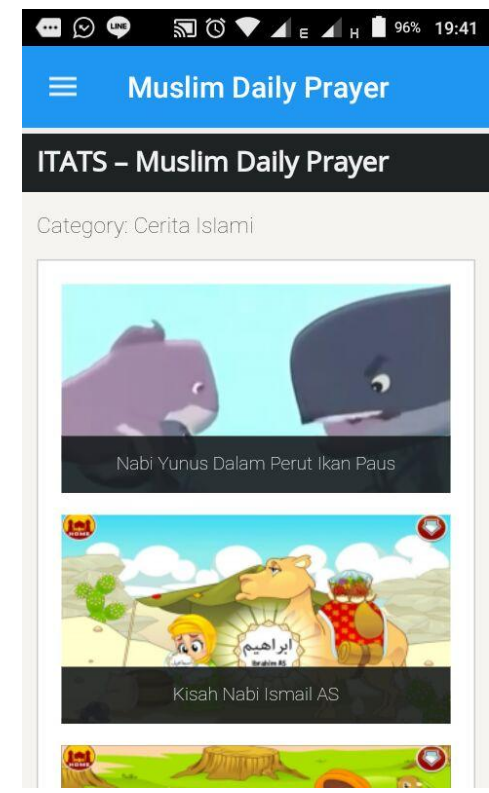

Gambar 3. Tampilan Menu Cerita Islami

Gambar 3 merupakan salah satu cerita yang disajikan dalam aplikasi Muslim Daily Prayer. Karakter dan tokoh yang diceritakan adalah cerita-cerita tentang kenabian dalam islam. 


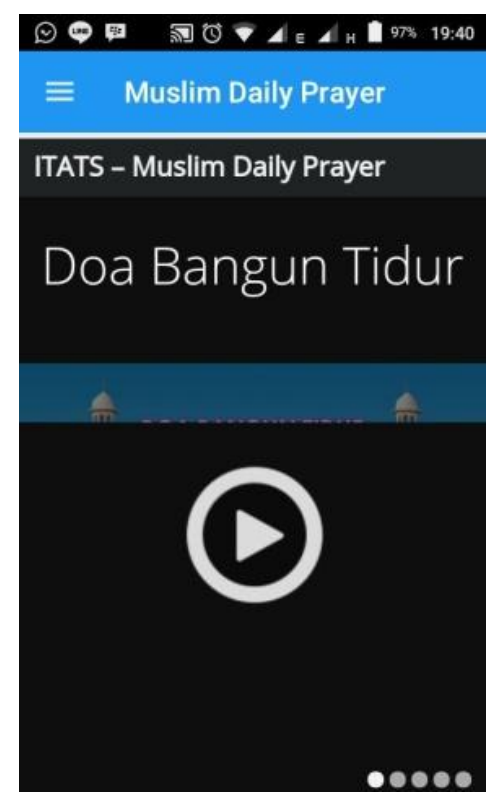

Gambar 4. Tampilan Menu Doa Sehari-Hari

Gambar 4 merupakan tampilan untuk menu doa sehari-hari. Doa-doa yang disajikan dalam aplikasi ini merupakan doa yang telah diajarkan di TPQ Al-Fadlol. Menu ini disajikan dalam bentuk audio-visual sehingga para santri bisa membaca doa serta mendengarkan pelafalan dari doa tersebut.

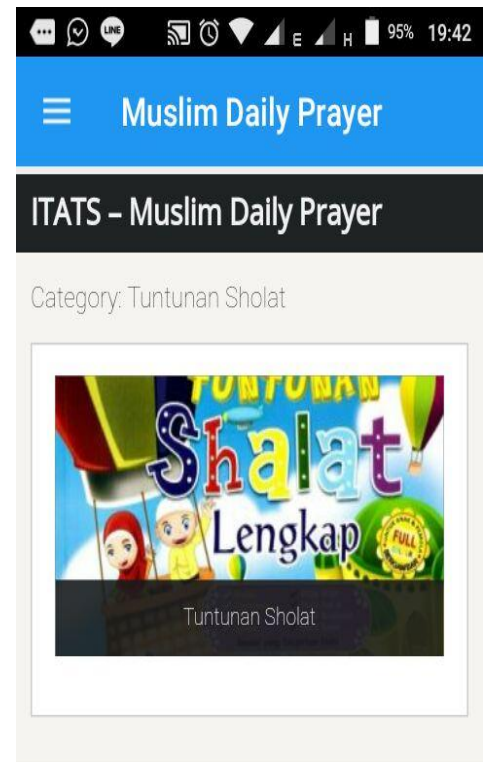

(a)

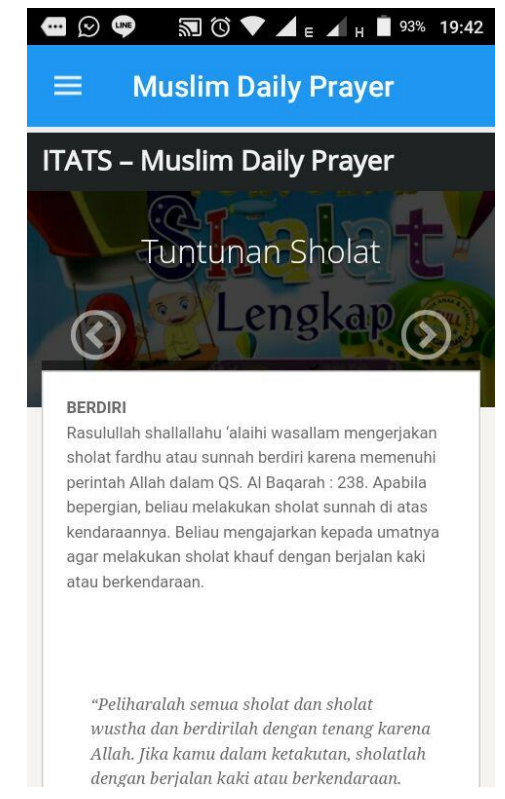

(b)

Gambar 5. Tampilan Menu Tuntunan Sholat

Gambar 5 merupakan tampilan dari menu Tuntunan Sholat. Pada menu ini, keterangan diberikan naratif sesuai dengan pedoman agama Islam. Pada tampilan ini, guru dituntut untuk mendampingi para santri dalam belajar gerakan-gerakan salat karena belum semua usia santri bisa membaca. 


\section{b. Dokumentasi Kegiatan}

Dua kegiatan utama yang diadakan tim PKM yaitu sosialisasi teknologi informasi dan pelatihan penggunaan aplikasi Muslim Daily Prayer telah dilakukan dengan lancar. Berikut ini diberikan beberapa dokumentasi dari kegiatan tersebut.

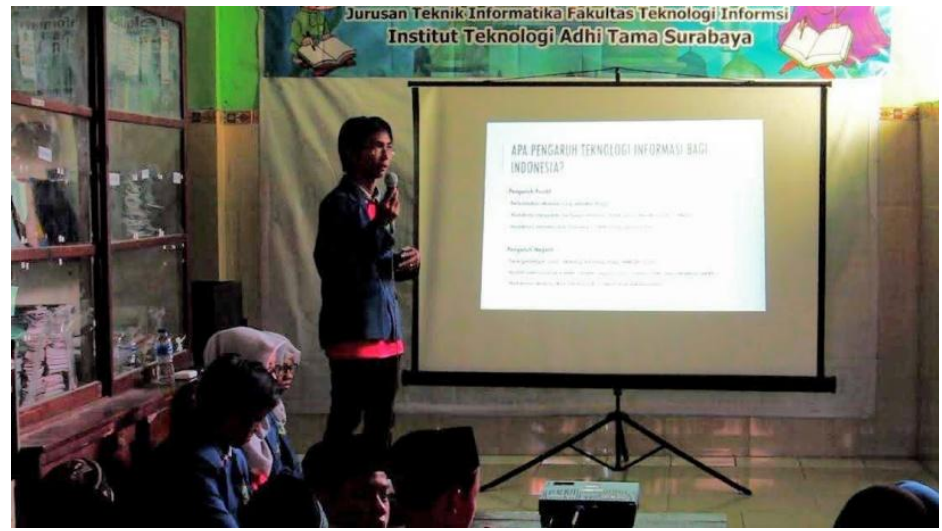

Gambar 6. Sosialisasi Tentang Teknologi Informasi

Gambar 6 menunjukkan bahwa salah satu anggota tim PKM sedang melakukan sosialisasi tentang teknologi informasi. Pentingnya teknologi informasi harus juga diimbangi dengan adanya pengetahuan penggunaan teknologi informasi dengan bijak.

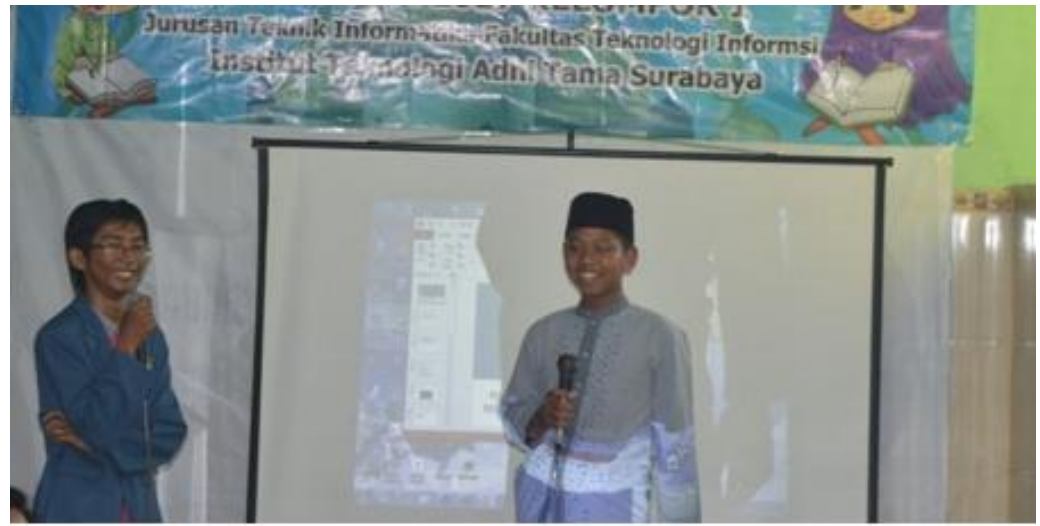

Gambar 7. Bentuk Interaktif Kegiatan

Salah satu cara untuk mengetahui pemahaman peserta terhadap materi kegiatan yang diberikan adalah dengan memberikan pertanyaan. Bisa dilihat pada Gambar 7, salah satu peserta memberikan respon terhadap pertanyaan yang diajukan.

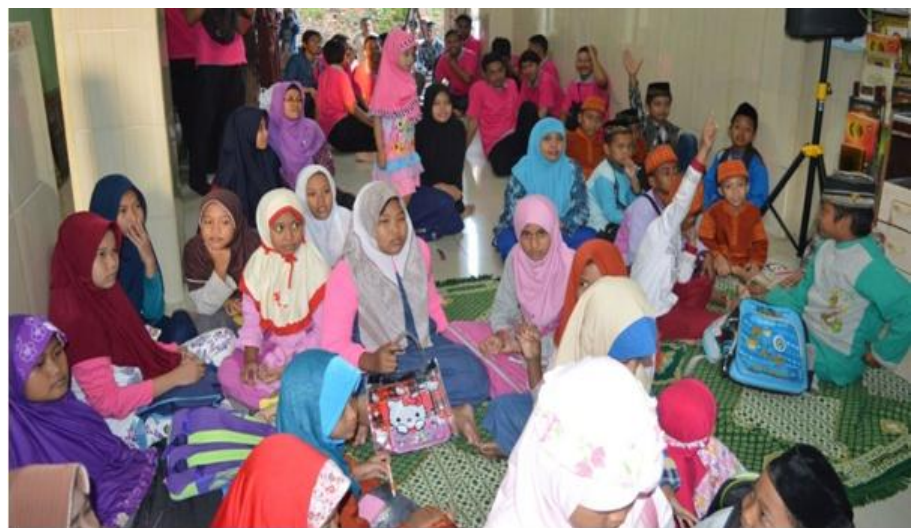

Gambar 8. Para Santri Peserta Kegiatan 
Kondisi peserta kegiatan PKM terlihat pada Gambar 8. Peserta terdiri atas para santri dan guru.

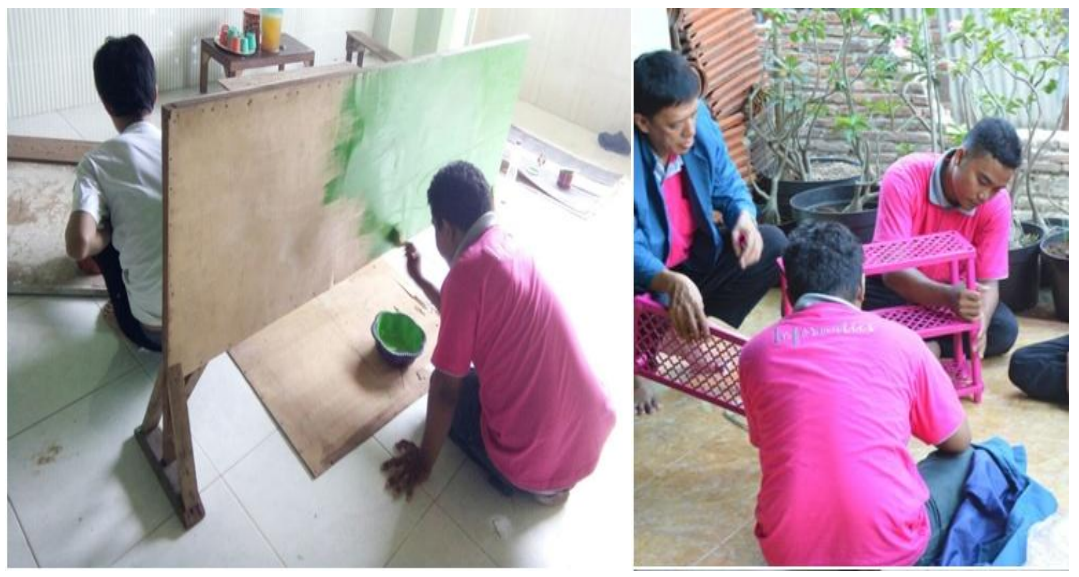

Gambar 9. Panitia Membantu Prasarana TPQ Al-Fadlol

Gambar 9 merupakan salah satu bentuk tali asih tim PKM untuk membantu prasarana TPQ Al-Fadlol.

\section{Kesimpulan}

Kegiatan pengabdian kepada masyarakat dengan tema pemanfaatan teknologi informasi untuk pembelajaran di TPQ Al-Fadlol telah selesai dilaksanakan dengan beberapa kesimpulan berikut.

1. Aplikasi Muslim Daily Prayer yang telah diluncurkan bisa membantu para guru untuk membuat pembelajaran ibadah sehari-hari lebih menyenangkan.

2. Para santri dan juga guru di TPQ Al-Fadlol sudah memiliki pemahaman terhadap pengaruh negatif dan positif dari teknologi informasi sehingga mampu membantu mereka dalam menyaring setiap informasi yang diperoleh. Selain itu, mereka dapat menggunakan teknologi untuk kebutuhan yang bermanfaat.

\section{Ucapan Terima Kasih}

Tim PKM mengucapkan terima kasih yang sebesar-besarnya kepada Jurusan Teknik Informatika, Institut Teknologi Adhi Tama Surabaya yang telah mendukung terlaksananya kegiatan pengabdian ini. Terima kasih juga diucapkan untuk TPQ Al-Fadlol yang telah mengizinkan tim PKM memberikan kontribusi ilmu yang dimiliki.

\section{Daftar Pustaka}

Ameliola, S., \& Nugraha, H. D. (2015). F1 ( ppm ). Perkembangan Media Informasidan Teknologi Terhadap Perkembangan Anak, 2, 400.

Anonim. (2019). Taman Pendidikan Al-Qur'an. Retrieved from https://id.wikipedia.org/wiki /Taman_Pendidikan_Al-Qur\%27an

Budiman, H. (2017). Peran Teknologi Informasi Dan Komunikasi Dalam Pendidikan. Al-Tadzkiyyah: Jurnal Pendidikan Islam, 8(1), 31. https://doi.org/10.24042/atjpi.v8i1.2095

Muhson, A. (2010). Pengembangan Media Pembelajaran Berbasis Teknologi Informasi. Jurnal Pendidikan Akuntansi Indonesia, 8(2). https://doi.org/10.21831/jpai.v8i2.949

Nurseto, T. (2012). Membuat Media Pembelajaran yang Menarik. Jurnal Ekonomi Dan Pendidikan, 8(1), 19-35. https://doi.org/10.21831/jep.v8i1.706 


\section{Afiliasi:}

Maftahatul Hakimah*, Tukadi, Rinci Kembang Hapsari, Hendro Nugroho, Dian Puspita Hapsari Jurusan Teknik Informatika, Institut Teknologi Adhi Tama Surabaya

Jl. Arief Rahman Hakim 100, Surabaya, Jawa Timur

E-mail : hakimahmafta@gmail.com*, tukadi@itats.ac.id,rincikembang@itats.ac.id, dosh3ndro@itats.ac.id,dian.puspita@itats.ac.id 